\title{
Characterization of pigmented and non-pigmented flakes glutinous rice (ampiang) on chemical compositions, free fatty acids compositions, amino acids compositions, dietary fiber content, and antioxidant properties
}

\author{
Wiwit AMRINOLA ${ }^{1,2 *} \mathbb{D}$, Azis Boing SITANGGANG ${ }^{1}$, Feri KUSNANDAR ${ }^{1}$, Slamet BUDIJANTO ${ }^{1}$
}

\begin{abstract}
The purpose of this study was to compare the characteristics of flakes rice made pigmented and non-pigmented glutinous rice grain on chemical composition, fatty acid, amino acid, dietary fiber, and antioxidant properties. Flakes glutinous rice (FGR) made glutinous rice grain that has been pre-roasted and then flattened. This product contains an endosperm and rice bran layer. So that, it is rich in nutrients and bioactive compounds that have antioxidant properties that are beneficial to health. The process of making flakes rice is carried out in four stages, that is the process of soaking, roasting, flattening, and sifting process. The grain used in this study are pigmented (red and black) and non-pigmented glutinous rice grains. The results showed that black FGR contained higher ash content, crude protein, dietary fiber, total phenolic compounds, flavonoids, $\gamma$-oryzanol, anthocyanins, and antioxidants activity. Meanwhile, white FGR is highest in fat, carbohydrate, and amylose content amongst others. Furthermore, FGR is rich in essential fatty acids (oleic and linoleic), glutamic acid, essential amino acids (Leucine, Arginine, and Phenylalanine). In conclusion, pigmented FGR has higher nutritional value, antioxidant properties, and antioxidants activity than non-pigmented FGR.
\end{abstract}

Keywords: flakes glutinous rice; pigmented glutinous rice; non-pigmented glutinous rice; Ampiang; bioactive compounds.

Practical Application: Pigmented and non-pigmented glutinous flakes rice have the potential as a ready-to-eat food product that is rich in nutritional value and antioxidant properties.

\section{Introduction}

Rice is the staple food for Indonesian people. Various methods have been used to produce rice that is suitable for consumption and has high nutritional value, one of which is the direct processing of grains into flakes rice (Roy et al., 2011; Kumar et al., 2016; Dahare et al., 2019). Generally, flakes rice is made of non-glutinous and non-pigmented rice grains but also this product can be made with glutinous rice grain (pigmented or non-pigmented), and can be called flakes glutinous rice. Flakes glutinous rice (FGR) is flake rice made glutinous rice grains that have been pre-roasted and then flattened. In West SumatraIndonesia, FGR also is known as ampiang (Kurniawan, 2015). It is usually made from pigmented (red) and non-pigmented glutinous rice grain.

The process of making FGR is carried out in four stages, that is the process of soaking the rice grains, the cooking process by roasting, the flattening process, and the sifting process. The soaking and roasting process causes the rice starch to undergo a gelatinization process before being flattened into flakes rice. The resulting flake rice still contains a layer of rice bran. Flakes rice is a precooked product that can be categorized as a readyto-eat product (Dahare et al., 2019) and is consumed directly by soaking or watering it first with boiled water and then filtered.
Flakes rice product that not only contains an endosperm but also contains a layer of rice bran. The endosperm of rice contains carbohydrates (starch) and protein (Deepa et al., 2010) while the bran layer is rich in bioactive components such as phenolic components, flavonoids, $\gamma$-oryzanol, dietary fiber, phytic acid, vitamins $B(B 1, B 3, B 6)$, tocopherols and tocotrienols, anthocyanins and proanthocyanins (specifically for pigmented rice), and minerals ( $\mathrm{Mg}, \mathrm{K}, \mathrm{Fe}$, and $\mathrm{Ca}$ ), essential fatty acids, and essential amino acids (Thammapat et al., 2015; Kumar et al., 2016; Huang \& Lai, 2016; Munarko et al., 2020). Furthermore, Kumar et al. (2016); Kumar \& Prasad (2017) explained that flakes rice is rich in carbohydrates (starch), protein, vitamins, minerals ( $\mathrm{Ca}, \mathrm{K}, \mathrm{Na}, \mathrm{Mg}$, and $\mathrm{Fe}$ ), fiber, resistant starch, phytochemical components such as $\gamma$-oryzanol, and essential amino acids. Its nutritional content is relatively higher than milled rice and relatively almost equivalent to brown rice, but its composition varies depending on the variety and processing method.

There are three types of local varieties of glutinous rice grains that are cultivated in West Sumatera, Indonesia, they are white as non-pigmented glutinous rice, red, and black glutinous rice as pigmented glutinous rice. The three types of glutinous rice that distinguish it is the number of anthocyanin compounds. Anthocyanin is a color pigment from the flavonoid group found in the rice bran layer. Anthocyanin and proanthocyanin compounds 
are reported to have physiological functions for the body, one of which is as an antioxidant compound (Sompong et al., 2011; Arab et al., 2011; Thammapat et al., 2015; Goufo \& Trindade, 2014). Furthermore, the researcher has been reported that pigmented rice (such as red, and black rice) contains higher total phenols, total flavonoids, $\gamma$-oryzanol, and anthocyanins compared to non-pigmented or white rice (Goufo \& Trindade, 2014; Shao \& Bao, 2015). Amrinola et al. (2021) also reported that pigmented glutinous rice had a much higher dietary fiber, total phenolic content, total flavonoids, $\gamma$-oryzanol, anthocyanins, and antioxidant activity than white glutinous rice.

Based on the description above, FGR has the potential to be developed. The diversity of raw materials will produce FGR with different characteristics. But unfortunately, until now there has been no research reporting FGR, especially those made from pigmented and non-pigmented glutinous rice grains. Therefore, the purpose of this study was to compare the chemical composition, fatty acid, amino acid, dietary fiber, and antioxidant properties of FGR made from pigmented and non-pigmented glutinous rice grains.

\section{Material dan methods}

\subsection{Materials}

This research used pigmented (red and black) and nonpigmented (white) local glutinous rice grains obtained directly from farmers in the Padang Panjang and Agam areas, West Sumatra, Indonesia. Chemical reagents for analysis (such as ethanol, methanol, hexane, $\mathrm{HCl}$, etc.) were obtained from Merck (PT. Merck Tbk, Indonesia) while DPPH and Quercetin were obtained from Sigma-Aldrich (Sigma-Aldrich Co., St. Loius, USA).

\subsection{Preparation of flaked glutinous rice}

The process of making FGR is done by soaking glutinous rice grains for 24 hours at room temperature. The ratio of soaking water and grain is $1: 2$. Then the soaking water is removed by filtering. After that, the cooking process is carried out by roasting using a clay pot. This roasting process is required a time of \pm 5 minutes. Furthermore, the rice grain that has undergone a gelatinization process is then flattened ( \pm 2 minutes) using a mortar and pestle to produce flakes rice. Finally, the sifting process is carried out to clean the remnants of the husks that are still mixed with the FGR.

\section{3 determination of chemical composition}

Proximate analysis was carried out using the (AOAC, 2005). Water content analysis used the gravimetric method, protein analysis used the Kjeldahl method, the crude fat analysis used the extraction method using Soxhlet, and analysis of ash content using the muffle furnace method at $550^{\circ} \mathrm{C}$. While the calculation of carbohydrate content is carried out using the by difference method. Meanwhile, analysis of amylose and amylopectin contents used the method of (Juliano, 1971). The amylopectin content was obtained from the difference between the starch content and the amylose content of the sample.

\subsection{Determination of fatty acid composition}

Fatty acid composition analysis was carried out using gas chromatography. A total of $5 \mathrm{~g}$ of the sample was weighed, then extracted using chloroform-methanol to obtain the oil. The extract was then methylated using $0.5 \mathrm{~N} \mathrm{NaOH}$-methanol. The methylated sample was injected into gas chromatography. Fatty acids were identified by the FID detector with SP 2380 capillary columns. The process conditions were $160-174{ }^{\circ} \mathrm{C}$ with a temperature increase of $2{ }^{\circ} \mathrm{C} / \mathrm{min}$, then a temperature of 174 to $190^{\circ} \mathrm{C}$ with a temperature increase of $1{ }^{\circ} \mathrm{C} / \mathrm{min}$. Other conditions are the FID temperature of $250^{\circ} \mathrm{C}$ and the carrier gas He with a pressure of $18 \mathrm{psi}$. The response generated is presented in the form of a chromatogram (peak) and the type of fatty acid is identified by comparing it with the chromatogram (peak) of a standard fatty acid (lipid standard: fatty acid methyl ester).

\subsection{Determination of amino acid composition}

Analysis of the amino acid composition of the FGR carried out by PT. Saraswanti Indo Genetech, Bogor, Indonesia using an internally developed method (18-5-17/MU SMM-SIG) using the UPLC instrument (Sitanggang et al., 2020a).

\subsection{Determination of dietary fiber}

Dietary fiber content analysis, the method used was a modified multi-enzyme method following AACC Method 32-21.01 (American Association of Cereal Chemist, 2009). In this method, total dietary fiber, insoluble dietary fiber (IDF), and soluble dietary fiber (SDF) fractions were determined. The sample is gelatinized first and then digested enzymatically using several enzymes that play a role in digestion. For Insoluble Dietary fiber, the residue is filtered and washed with distilled water. Filtration and washing saved. The residue (IDF) was washed with 95\% ethanol and acetone. After drying, the residue was weighed and ash using a kiln. IDF is the weight of the residue minus the weight of protein and ash. While the Soluble Dietary Fiber (SDF), the soluble fiber in the filtrate is precipitated. The precipitate was filtered and washed with $78 \% \mathrm{EtOH}, 95 \% \mathrm{EtOH}$, and acetone. After drying, the residue was weighed. Then ignited using a furnace. SDF is the weight of the residue minus the weight of protein and ash.

\subsection{Determination of antioxidant properties}

Antioxidant properties determined in this study included analysis of total phenol, total flavonoid, $\gamma$-oryzanol, anthocyanin, and antioxidant activity (IC50). Total phenol analysis (TPC) was carried out by extracting the sample. Then the analysis was carried out using Folin Ciocalteau reagent and $\mathrm{Na}_{2} \mathrm{CO}_{3}$ was added. The absorbance was measured at a wavelength of $725 \mathrm{~nm}$. Total flavonoid (TFC) was carried out by the colorimetric method (Chang et al., 2002). The flavonoid components were extracted using methanol and then the absorbance was measured using UV-VIS spectrophotometry with a wavelength of $431 \mathrm{nM}$. The flavonoid content obtained is equivalent to quercetin. Determination of $\gamma$-oryzanol was carried out by the partial extraction method (Lilitchan et al., 2008). samples were extracted with isopropanol using different volumes ( 4 and $8 \mathrm{~mL}$ ). The absorbance of the two 
supernatants was measured using a UV-vis spectrophotometer at $326 \mathrm{~nm}$. The concentration of $\gamma$-oryzanol was calculated by the equation:

$y=\frac{\mathrm{x} 1 \mathrm{x} 2}{2 \mathrm{x} 1-\mathrm{x} 2}$

Where $\mathrm{x}$ is the amount (g) of $\gamma$-oryzanol in the extract with different isopropanol volumes, and $y$ is the total amount of $\gamma$-oryzanol in FGR.

Meanwhile, anthocyanin analysis was carried out using the differential pH method (Giusti \& Wrolstad, 2001). The absorbance of the two $\mathrm{pH}$ treatments was measured using a spectrophotometer at $516 \mathrm{nM}$ and $700 \mathrm{nM}$ wavelengths. The anthocyanin concentration was calculated as cyanidin-3glycoside using a molar extension coefficient of $29,600 \mathrm{~L} / \mathrm{cm}$ and a molecular weight of $448.8 \mathrm{~g} / \mathrm{mol}$. Subsequently, the antioxidant activity was determined using the DPPH (1,1-diphenyl-2picrylhydrazil) method. The principle of this determination is that antioxidant compounds will react with DPPH radicals through a hydrogen atom donation mechanism and cause the color of $\mathrm{DPPH}$ to decay from purple to yellow. Active compounds as antioxidants will reduce DPPH free radicals to diphenyl pikryl hydrazine (Sitanggang et al., 2020b).

\subsection{Statistical analysis}

The statistical analysis (analysis of variance or ANOVA) was performed using SPSS for Windows Version 24.0 (IBM, US). If the mean differences existed, multiple comparisons were performed using the Duncan's Multiple Range Test (DMRT) were employed with a confidence level of $95 \%$.

\section{Results and discussion}

\subsection{Determination of chemical compositions}

The results of the proximate analysis of the three types of FGR in this research are presented in Table 1. In the table can be seen that FGR is rich in nutrients. The crude protein and ash content of FGR is quite high. The black FGR has the highest crude protein and ash content compared to others. Meanwhile, the lowest protein content is found in red FGR and the lowest ash content is in white FGR. While the one with the highest crude fat content is white FGR, and the lowest crude fat is red FGR. This result is slightly different from the non-pigmented and nonglutinous flaked rice that was reported by Kumar et al. (2016) had a $5.95 \mathrm{~g} / 100 \mathrm{~g}$ protein content, $1.73 \%$ total ash, and $3.44 \%$ crude fat. The differences can be caused by differences in the varieties used and the conditions of the processing carried out.

The water content of FGR ranged from $8.75-10.27 \%$. This result was comparable to the moisture content of flaked rice reported by Kumar et al. (2016), which is $10.20 \%$. The decrease in the water content of the FGR in this research is influenced by the roasting and the flattening process carried out. Further, Dutta et al. (2016) also reported that the roasting process will cause the water content of the grain to decrease from $\pm 30 \%$ to $11-12 \%$ (wb).

Table 1 shows that the amylose content of each FGR differ from carbohydrate content is significantly different, where the highest one is white FGR $(6.88 \%)$ and the lowest is red FGR (5.69\%). These results indicate that FGR is made from glutinous rice which has a very low amylose content or waxy, in contrast to other flakes rice such as Poha. Kumar \& Prasad (2017) reported that flakes rice (Poha) has an amylose content of $20.05 \%$. the content of amylose and amylopectin is closely related to the ability of starch to form hydrogen bonds and absorb water. The higher the amylose content in a material, the greater the starch's ability to form hydrogen bonds and absorb water. In addition, amylose content is also used as a parameter to predict the texture of cooked rice (Okotomo et al., 2002; Suwannaporn et al., 2007; Kang et al., 2010).

\subsection{Determination of fatty acid composition}

The carbon chains in the fatty acid structure can be in the form of saturated fatty acids (SFAs) or unsaturated fatty acids. Saturated fatty acids are composed of a chain of single-bonded carbon atoms (MUFAs) or more than one double-bonded carbon atom. (PUFAs) (Orsavova et al., 2015). Our bodies are unable to synthesize PUFAs, so these fatty acids must be obtained from the food consumed. The results of the analysis of the fatty acid composition of the three types of FGR are presented in Table 2.

In Table 2 it can be seen that the types of saturated fatty acids detected in each type of FGR are slightly different. The types of fatty acids detected in white FGR and red FGR ranging from medium-chain to long-chain saturated fatty acids. However, the

Table 1. Chemical composition of flakes glutinous rice (FGR).

\begin{tabular}{|c|c|c|c|c|}
\hline \multirow{2}{*}{ No. } & \multirow{2}{*}{ Parameters } & \multicolumn{3}{|c|}{ Types of flakes glutinous rice (FGR) } \\
\hline & & White FGR & Red FGR & Black FGR \\
\hline 1. & Moisture content $(\% \mathrm{db})$ & $9.60 \pm 0.22 b$ & $10.27 \pm 0.09 c$ & $8.75 \pm 0.07 \mathrm{a}$ \\
\hline 3. & Crude Fat $(\% \mathrm{db})$ & $1.97 \pm 0.02 \mathrm{c}$ & $1.72 \pm 0.03 \mathrm{a}$ & $1.81 \pm 0.03 \mathrm{~b}$ \\
\hline 4. & Crude Protein $(\% \mathrm{db})$ & $7.78 \pm 0.03 a$ & $7.65 \pm 0.11 \mathrm{a}$ & $8.09 \pm 0.01 b$ \\
\hline 7. & Amylopectin content (\%) & $93.12 \pm 0.50 \mathrm{a}$ & $94.31 \pm 0.36 \mathrm{~b}$ & $94.06 \pm 0.27 \mathrm{~b}$ \\
\hline
\end{tabular}

Different letters in the same row between corresponding pairs indicate a significant difference $(\mathrm{p}<0.05)$ by Duncan's test. 
Table 2. Fatty acid composition of flakes glutinous rice (FGR).

\begin{tabular}{|c|c|c|c|c|c|}
\hline No & Fatty acids & FA shorthand & White FGR & Red FGR & Black FGR \\
\hline \multicolumn{6}{|c|}{ Saturated fatty acids } \\
\hline 1 & Butyric acid (\%) & $\mathrm{C} 4: 0$ & ND & ND & 0.122 \\
\hline 2 & Caprylic acid (\%) & C8:0 & ND & ND & 0.935 \\
\hline 3 & Capric acid (\%) & $\mathrm{C} 10: 0$ & ND & ND & 0.465 \\
\hline 4 & Myristic acid (\%) & C14:0 & 0.513 & 0.395 & 0.249 \\
\hline 5 & Palmitic acid (\%) & $\mathrm{C} 16: 0$ & 17.685 & 19.472 & 18.114 \\
\hline 6 & Stearic acid (\%) & $\mathrm{C} 18: 0$ & 1.360 & 2.137 & 1.720 \\
\hline 7 & Arachidic acid (\%) & $\mathrm{C} 20: 0$ & 0.635 & 0.836 & 0.758 \\
\hline 8 & Behenic acid (\%) & $\mathrm{C} 22: 0$ & 0.259 & 0.308 & 0.271 \\
\hline 9 & Lignocerat (\%) & $\mathrm{C} 24: 0$ & 0.437 & 0.616 & 0.614 \\
\hline \multicolumn{3}{|c|}{ Total of saturated fatty acid (\%) } & 20.893 & 23.769 & 23.247 \\
\hline \multicolumn{6}{|c|}{ Unsaturated fatty acid } \\
\hline 1 & Oleic acid (\%) & $\mathrm{C} 18: 1$ & 35.401 & 36.858 & 32.146 \\
\hline 2 & Linoleic acid (\%) & $\mathrm{C} 18: 2$ & 32.386 & 36.899 & 33.612 \\
\hline 3 & Linolenic acid (\%) & $\mathrm{C} 18: 3$ & 1.239 & 2.532 & 1.626 \\
\hline 4 & Eicosanoic acid (\%) & C20:1 & 0.365 & 0.337 & 0.348 \\
\hline \multicolumn{3}{|c|}{ Monounsaturated fatty acids (MUFAs) (\%) } & 35.77 & 37.195 & 32.494 \\
\hline \multicolumn{3}{|c|}{ Poliunsaturated fatty acids (PUFAs) (\%) } & 33.625 & 39.431 & 35.238 \\
\hline \multicolumn{3}{|c|}{ Total of unsaturated fatty acid (\%) } & 69.477 & 76.626 & 67.732 \\
\hline
\end{tabular}

$\mathrm{ND}=$ not detected.

types of saturated fatty acids detected in the black FGR were more numerous, that is from short-chain saturated fatty acids to long-chain fatty acids. The difference in fatty acid composition is due to the hydrolysis of fats caused by the activity of the lipase enzyme and heating during the FGR production process, causing the breaking of the ester bond and the release of free fatty acids.

The type of saturated fatty acid with the highest amount of content in the three types of FGR is the same, that is palmitic acid. Meanwhile, the type of unsaturated fatty acid with the highest amount of content in the three types of FGR is linoleic acid and followed by oleic acid. These results are appropriate with Kang et al. (2010); Gines et al. (2016) that have been reported, the fatty acids detected in the bran of several types of rice ranged from medium-chain saturated fatty acids to long-chain saturated fatty acids, where the highest type of saturated fatty acid was palmitic acid, while the highest types of unsaturated fatty acids were also oleic and linoleic.

In Table 2 can be seen that the MUFAs and PUFAs content in the three types of FGR in this research was higher than the SFA content. MUFA and PUFA have an important role in health. Meanwhile, the high content of PUFAs in oil indicates the high nutritional quality of the oil (Gines et al., 2016).

\subsection{Determination of amino acids composition}

Protein quality is assessed from the comparison of essential and non-essential amino acids contained in these proteins. Proteins that are rich in essential amino acids are considered to have good quality (Amankwah et al., 2015; Amagliani et al., 2017). In Figure 1, it can be seen that the most dominant types of amino acids in the three types of FGR are the same, that is glutamic acid (Glu) from the non-essential amino acid group and leucine (Leu) from the essential amino acid group. The highest content of these two types of amino acids is found in the black FGR. While the lowest types of amino acids in these three types of FGR are not the same, that is white FGR the lowest is methionine (Met), while in red FGR and black FGR is cysteine (Cys). This result was comparable with the dominant amino acid in several varieties of local Korean white glutinous rice that was reported by Kang et al. (2010) was glutamate and asparagine (Asn), whereas the lowest is methionine (Met) and phenylalanine (Phe).

Glutamic acid is an amino acid that contributes to the characteristic flavor of foods. Kawai et al. (2009) reported that L-Glutamate (Glu) can provide a high-intensity savory (umami) flavor to food, specifically if it is in the form of Na-glutamate. Umami taste has been used to make food palatable all over the world. Dajanta et al. (2011) explained that the contribution of amino acids to flavor is also influenced by the polarity and structure or configuration ( $\mathrm{L}$ or $\mathrm{D}$ ) of the amino acid.

Chaudhari et al. (2018) explained that rice is rich in essential amino acids and high protein digestibility. These amino acids build resilient muscles which come back to their original form after stretching and bending, healthy skin and hair, and clearer eyesight and nourish the heart and lungs, tendons and ligaments, brain, nervous system, and glandular network. The three types of FGR contain all types of essential amino acids needed by the body. This figure shows that pigmented FGR is rich in essential amino acids. The dominant essential amino acids in glutinous rice are Leucine (Leu), followed by Arginine 


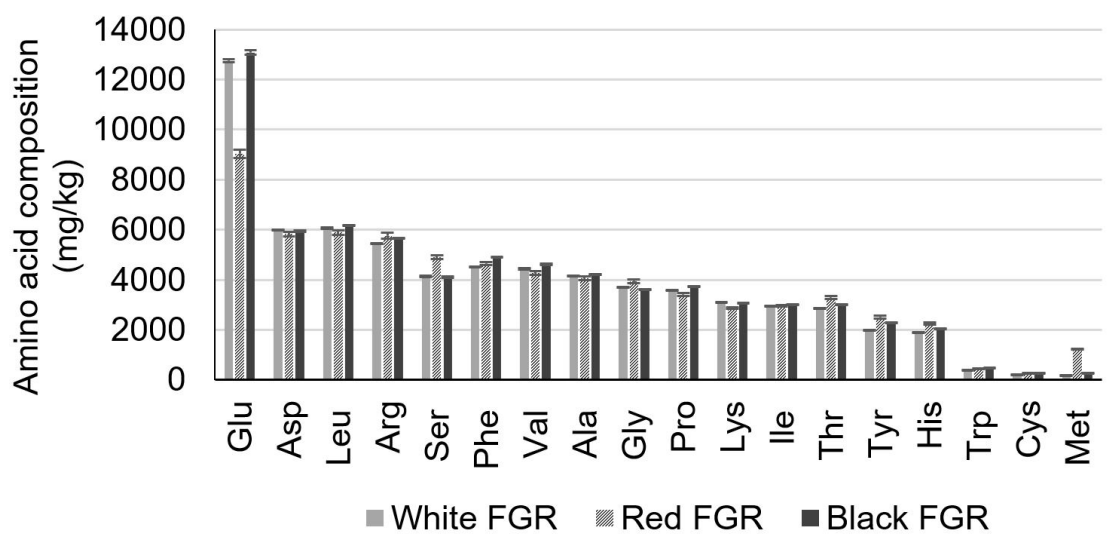

Figure 1. Amino acid composition of flakes glutinous rice.

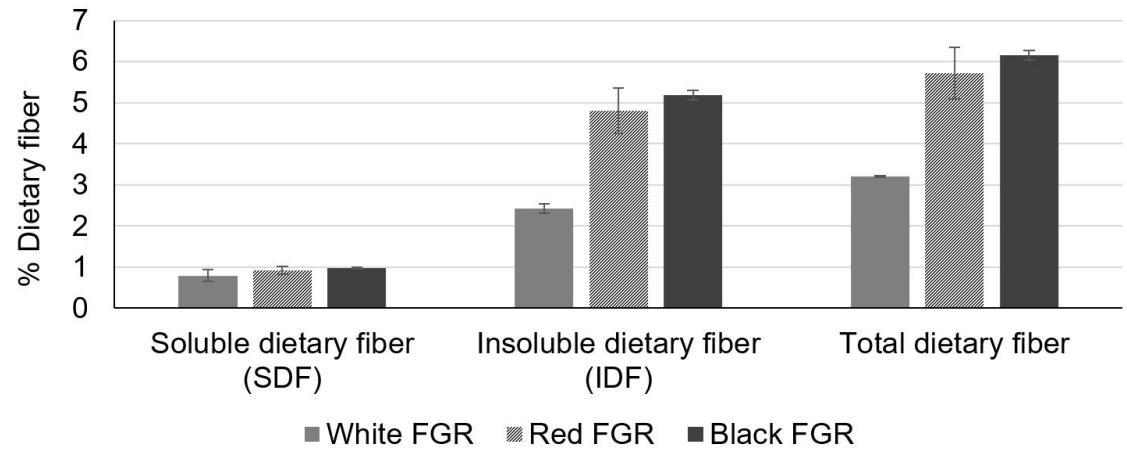

Figure 2. Dietary fiber of flakes glutinous rice (FGR).

(Arg) and Phenylalanine (Phe). Wu et al. (2009) reported that these dominant essential amino acids have an important role in health. Furthermore, these three types of FGR also have a fairly high lysine (Lys) and histidine (His) content. Histidine is an essential amino acid for children's growth and lysine is often used as an indicator of food quality degradation because it is easier to engage in Maillard reaction (Yang et al., 2016).

Based on the results of the analysis of the amino acid composition, the three types of FGR do not have to limit amino acids because they meet the adequacy score for all types of amino acids required for each day based on FAO/WHO standards, especially for histidine, isoleucine, leucine, lysine, threonine, tryptophan, valine, sulfur amino acids (methionine, cysteine), and aromatic amino acids (phenylalanine, tyrosine) (Food and Agriculture Organization, 2013).

\subsection{Determination of dietary fiber}

Dietary fiber cannot be digested and absorbed by the intestines but has a very important function for health. Soluble dietary fiber (SDF) functions to slow down the speed of digestion in the intestines, provide a longer feeling of fullness, and slow the appearance of blood glucose so that insulin is needed to transfer glucose into the body's cells and be converted be less energy. While insoluble dietary fiber (IDF) serves to prevent various diseases related to the intestine, diverticulosis, and colon cancer. Rice with high dietary fiber (especially SDF) will reduce the speed of starch digestion in the intestine.

The dietary fiber content of each FGR is presented in Figure 2. Black FGR has the highest total dietary fiber content compared to red FGR and white FGR. The dominant type of fiber in the three types of FGR is IDF, which reaches $70 \%-84 \%$ of the total dietary fiber contained in FGR. The pigmented FGR (black and red) have a total content of dietary fiber and IDF which are not statistically significantly different, but both are significantly different with white FGR (non-pigmented). The results of the analysis of the total dietary fiber in FGR, were higher than the total dietary fiber content in brown rice and black rice reported by Sompong et al. (2011), which is $3.75 \%$ in brown rice and $3.41 \%$ in black rice. One of the causes of the difference in the total fiber content of this food is due to the different varieties used and the processing process.

\subsection{Determination of antioxidant properties}

Antioxidant activity is related to the content of bioactive components contained in a food ingredient. One of the physiological effects of bioactive compounds is to have antioxidant activity that is good for the body. The main antioxidant compounds in rice are grouped into six groups, they are total phenolic acids, flavonoids, anthocyanins and proanthocyanins, tocopherols and tocotrienols, $\gamma$-oryzanol, phytic acid (Goufo \& Trindade, 2014). 
Table 3. Compound exhibiting antioxidant properties and antioxidant $\mathrm{IC}_{50}$ of flakes glutinous rice (FGR).

\begin{tabular}{ccccc}
\hline \multirow{2}{*}{ No. } & \multirow{2}{*}{ Parameters $(\% \mathrm{db})$} & \multicolumn{3}{c}{ Types of flakes glutinous rice (FGR) } \\
\cline { 3 - 5 } & Total Phenolic acid $(\mathrm{mg}$ GAE/g FGR) & $0.573 \pm 0.008 \mathrm{a}$ & $0.694 \pm 0.019 \mathrm{~b}$ & $0.962 \pm 0.022 \mathrm{c}$ \\
\hline 1. & Thite FGR & $2.052 \pm 0.026 \mathrm{~b}$ & $2.143 \pm 0.039 \mathrm{c}$ \\
2. & Total Flavonoids Compound $(\mathrm{mg}$ Quercetin/g) & $1.892 \pm 0.009 \mathrm{a}$ & $0.409 \pm 0.01 \mathrm{~b}$ & $0.731 \pm 0.01 \mathrm{c}$ \\
3. & $\gamma$-Oryzanol $(\mathrm{mg} / \mathrm{g})$ & $0.509 \pm 0.03 \mathrm{a}$ & $0.278 \pm 0.0035 \mathrm{~b}$ & $0.363 \pm 0.0038 \mathrm{c}$ \\
4. & Anthocyanin $(\mathrm{mg} \mathrm{CyE} / \mathrm{g})$ & $0.007 \pm 0.0018 \mathrm{a}$ & $73.33 \pm 0.63$ & $26.11 \pm 2.45$ \\
5 & Antioxidant activity $\left(\mathrm{IC}_{50}\right)(\mathrm{ppm})$ & $619.68 \pm 13.43$ & \\
\hline
\end{tabular}

Different letters in the same row between corresponding pairs indicate a significant difference $(<0.05)$ by Duncan's test.

The results of testing the antioxidant activity of the three types of FGR can be seen in Table 3. The results of this study showed that the antioxidant activity of FGR was significantly different for each type of FGR produced. The black FGR has a very good inhibitory ability, while the red FGR and white FGR have good inhibitory power. The results of the antioxidant activity test using $\mathrm{IC}_{50}$ also showed results that were directly proportional to the inhibitory power, where it was found that black FGR only needed $26.11 \mathrm{ppm}$ to be able to actively ward off free radicals, while red FGR needed $73.33 \mathrm{ppm}$ and white FGR needed $619.68 \mathrm{ppm}$ to be able to ward off free radicals. The results of this antioxidant activity test were positively correlated with the content of its antioxidant components, namely total phenols, flavonoids, $\gamma$-oryzanol, and anthocyanins.

In Table 3 it can be seen that the total content of phenolic acids, flavonoids, $\gamma$-oryzanol, and anthocyanins in the three types of FGR was significantly different based on the type or color of the rice. Black FGR has the highest total content of phenolic acids, flavonoids, $\gamma$-oryzanol, and anthocyanins compared to red FGR, and then white FGR. Goufo \& Trindade (2014); Shao $\&$ Bao (2015) stated that the content of phenolic acid in rice correlated with the color of the rice. Pigmented rice such as red rice and black rice contains higher total phenolic compounds, flavonoids, $\gamma$-oryzanol, and anthocyanin than non-pigmented rice. Kumar et al. (2016) explain that the pre-cooking or parboiling process causes the amount of $\gamma$-Oryzanol content to increase compared to the raw material, but it is seen that the flaking process causes a decrease in the $\gamma$-oryzanol content of flaked rice products or extra thin flaked rice product.

\section{Conclusions}

In conclusion, flakes glutinous rice (FGR) is a flakes rice product that can be made from pigmented and non-pigmented glutinous rice grains. Overall, the three types of FGR in this research had high nutritional value, antioxidant properties, and antioxidant activity. However, pigmented FGR has higher than white FGR. Black FGR has a higher protein content, total ash, dietary fiber, antioxidant properties, and antioxidant activity compared to other types of FGR but is low in fat. These three types of FGR are also rich in essential fatty acids and essential amino acids needed by the body.

\section{References}

Amagliani, L., O’Regan, J., Kelly, A. L., \& O’Mahony, J. A. (2017). The composition, extraction, functionality and applications of rice proteins: a review. Trends in Food Science \& Technology, 64, 1-12. http://dx.doi.org/10.1016/j.tifs.2017.01.008.

Amankwah, E. N., Adu, E., John, B., \& Vm, D. (2015). Amino acid profiles of some varieties of rice, soybean and groundnut grown in ghana. Food Process Technol, 6(2), 6-8. http://dx.doi.org/10.4172/21577110.1000420 .

American Association of Cereal Chemist - AACC. (2009). AACC Approved Methods of Analysis: AACC 32-21.01; AACC 61-02.01. (11th ed). St.Paul, MN: AACC.

Amrinola, W., Sitanggang, A. B., Kusnandar, F., \& Budijanto, S. (2021). Characterization of three cultivars of Indonesian glutinous rice: a basis for developing rice-based functional food. The Annals of the University Dunarea de Jos of Galati. Fascicle VI, Food Technology, 45(1), 141-156. http://dx.doi.org/10.35219/foodtechnology.2021.1.10.

Arab, F., Alemzadeh, I., \& Maghsoudi, V. (2011). Determination of antioxidant component and activity of rice bran extract. Scientia Iranica, 18(6), 1402-1406. http://dx.doi.org/10.1016/j.scient.2011.09.014.

Association of Official Analytical Chemists - AOAC. (2005). Official methods of analysis of aoac international. AOAC 920.39C; AOAC 923.03; AOAC 495 925.09B; AOAC 992.23. Washington DC: AOAC.

Chang, C., Yang, M., Wen, H., \& Chern, J. (2002). Estimation of total flavonoid content in propolis by two complementary colorimetric methods. Yao Wu Shi Pin Fen Xi, 10(3), 178-182.

Chaudhari, P. R., Tamrakar, N., Singh, L., Tandon, A., \& Sharma, D. (2018). Rice nutritional and medicinal properties: a review article. Journal of Pharmacognosy and Phytochemistry, 7(2), 150-156.

Dahare, R., Sadu, B., \& Patel, S. (2019). Effect on physical, chemical, and functional characteristics during transformation of paddy to flaked rice: (POHA). International Journal of Chemical Studies, 7(8), 73-80.

Dajanta, K., Apichartsrangkoon, A., Chukeatirote, E., \& Frazier, R. A. (2011). Free-amino acid profiles of thua nao, a Thai fermented soybean. Food Chemistry, 125(2), 342-347. http://dx.doi.org/10.1016/j. foodchem.2010.09.002.

Deepa, G., Singh, V., \& Naidu, K. A. (2010). A comparative study on starch digestibility, glycemic index and resistant starch of pigmented ("Njavara" and 'Jyothi') and a non-pigmented ('IR 64') rice varieties. Journal of Food Science and Technology, 47(6), 644-649. http://dx.doi. org/10.1007/s13197-010-0106-1. PMid:23572699.

Dutta, H., Mahanta, C. L., Singh, V., Das, B. B., \& Rahman, N. (2016). Physical, physicochemical and nutritional characteristics of Bhoja chaul, a traditional ready-to-eat dry heat parboiled rice product processed by an improvised soaking technique. Food Chemistry, 191, 152-162. http://dx.doi.org/10.1016/j.foodchem.2014.10.144. PMid:26258715.

Food and Agriculture Organization - FAO. (2013). Dietary protein quality evaluation in human nutrition: report of an FAO expert consultaation. FAO Food and Nutrition Paper, 92. Retrieved from 
http://www.fao.org/ag/humannutrition/35978-02317b979a686a57 aa4593304ffc17f06.pdf

Gines, B., Gray, J., \& Abugri, D. (2016). Preliminary comparison of fatty acid composition (s) of selected commercial rice brands commonly consumed in north america. Austin Journal of Nutrition and Food Sciences, 4(1), 1-5.

Giusti, M. M., \& Wrolstad, R. E. (2001). Characterization and measurement of anthocyanins by uv-visible spectroscopy. Current Protocols in Food Analytical Chemistry, F1.2.1-F1.2.13, 1-13.

Goufo, P., \& Trindade, H. (2014). Rice antioxidants: phenolic acids, flavonoids, anthocyanins, proanthocyanidins, tocopherols, tocotrienols, $\gamma$-oryzanol, and phytic acid. Food Science \& Nutrition, 2(2), 75-104. http://dx.doi.org/10.1002/fsn3.86. PMid:24804068.

Huang, Y., \& Lai, H. (2016). Bioactive compounds and antioxidative activity of colored rice bran. Journal of Food And Drug Analysis, 24(3), 564-574. PMid:28911562.

Juliano, B. O. (1971). A simplified assay for millied-rice amylose. Cereal Foods World, 16(10), 334-360.

Kang, M. Y., Rico, C., \& Lee, S. C. (2010). Physicochemical properties of eight popular glutinous rice varieties in Korea. Plant Production Science, 13(2), 177-184. http://dx.doi.org/10.1626/pps.13.177.

Kawai, M., Uneyama, H., \& Miyano, H. (2009). Taste-active components in foods, with concentration on umami compounds. Journal of Health Science, 55(5), 667-673. http://dx.doi.org/10.1248/jhs.55.667.

Kumar, S., \& Prasad, K. (2017). Optimization of flakes rice dry roasting in common salt and studies on associated changes in chemical, nutritional, optical, physical, rheological, and textural attributes. Asian Journal of Chemistry, 29(6), 1380-1392. http://dx.doi.org/10.14233/ ajchem.2017.20563.

Kumar, S., Haq, R., \& Prasad, K. (2016). Studies on physico-chemical, functional, pasting and morphological characteristics of developed extra thin flaked rice. Journal of the Saudi Society of Agricultural Sciences, 17(3), 259-267.

Kurniawan, R. O. (2015). Nikmatnya olahan ketan susu khas Minang. Retrieved from https://travel.kompas.com/read/2015/02/24/171800027/ nikmatnya.olahan.ketan.susu.khas.minang

Lilitchan, S., Tangprawat, C., Aryusuk, K., Krisnangkura, S., Chokmoh, S., \& Krisnangkura, K. (2008). Partial extraction method for the rapid analysis of total lipids and $\gamma$-oryzanol contents in rice bran. Food Chemistry, 106(2), 752-759. http://dx.doi.org/10.1016/j. foodchem.2007.06.052.

Munarko, H., Sitanggang, A. B., Kusnandar, F., \& Budijanto, S. (2020). Phytochemical, fatty acid and proximal composition of six selected Indonesian brown rice varieties. CYTA: Journal of Food, 18(1), 336343. http://dx.doi.org/10.1080/19476337.2020.1754295.
Okamoto, K., Kobayashi, K., Hirasawa, H., \& Umemoto, T. (2002). Structural differences in amylopectin affect waxy rice processing. Plant Production Science, 5(1), 45-50.

Orsavova, J., Misurcova, L., Ambrozova, J. V., Vicha, R., \& Mlcek, J. (2015). Fatty acids composition of vegetable oils and its contribution to dietary energy intake and dependence of cardiovascular mortality on dietary intake of fatty acids. International Journal of Molecular Sciences, 16(6), 12871-12890. http://dx.doi.org/10.3390/ijms160612871. PMid:26057750.

Roy, P., Orikasa, T., Okadome, H., Nakamura, N., \& Shiina, T. (2011). Processing conditions, rice properties, health and environment. International Journal of Environmental Research and Public Health, 8(6), 1957-1976. http://dx.doi.org/10.3390/ijerph8061957. PMid:21776212.

Shao, Y., \& Bao, J. (2015). Polyphenols in whole rice grain: genetic diversity and health benefits. Food Chemistry, 180, 86-97. http:// dx.doi.org/10.1016/j.foodchem.2015.02.027. PMid:25766805.

Sitanggang, A. B., Lesmana, M., \& Budijanto, S. (2020b). Membranebased preparative methods and bioactivities mapping of tempe-based peptides. Food Chemistry, 329, 127193. http://dx.doi.org/10.1016/j. foodchem.2020.127193. PMid:32516711.

Sitanggang, A. B., Sinaga, W. S. L., Wie, F., Fernando, F., \& Krusong, W. (2020a). a. Enhanced antioxidant activity of okara through solid state fermentation of GRAS fungi. Food Science Technology, 40(1), 178-186. http://dx.doi.org/10.1590/fst.37218.

Sompong, R., Siebenhandl-Ehn, S., Linsberger-Martin, G., \& Berghofer, E. (2011). Physicochemical and antioxidative properties of red and black rice varieties from Thailand, China and Sri Lanka. Food Chemistry, 124(1), 132-140. http://dx.doi.org/10.1016/j.foodchem.2010.05.115.

Suwannaporn, P., Pitiphunpong, S., \& Champangern, S. (2007). Classification of rice amylose content by discriminant analysis of physicochemical properties. Starch, 59(3-4), 171-177.

Thammapat, P., Meeso, N., \& Siriamornpun, S. (2015). Effects of $\mathrm{NaCl}$ and soaking temperature on the phenolic compounds, $\alpha$-tocopherol, $\gamma$-oryzanol and fatty acids of glutinous rice. Food Chemistry, 175, 218-224. http://dx.doi.org/10.1016/j.foodchem.2014.11.146. PMid:25577073.

Wu, G., Bazer, F. W., Davis, T. A., Kim, S. W., Li, P., Rhoads, J. M., Satterfield, M. C., Smith, S. B., Spencer, T. E., \& Yin, Y. (2009). Arginine metabolism and nutrition in growth, health and disease. Amino Acids, 37(1), 153-168. http://dx.doi.org/10.1007/s00726008-0210-y. PMid:19030957.

Yang, L., Zhou, Y., Wu, Y., Meng, X., Jiang, Y., Zhang, H., \& Wang, H. (2016). Preparation and physicochemical properties of three types of modified glutinous rice starches. Carbohydrate Polymers, 137, 305313. http://dx.doi.org/10.1016/j.carbpol.2015.10.065. PMid:26686134. 